\title{
Climate change and water resources management in the coastal sub-basin of El Jadida Safi, Morocco
}

\author{
Mounia El Azhari ${ }^{1, *}$, and Dalila Loudyi ${ }^{2}$ \\ ${ }^{1}$ Hydraulic basin agency of Oum Er-Rbia (HBAOER), Morocco \\ ${ }^{2}$ Univ. Hassan II of Casablanca, Faculty of Sciences and Techniques of Mohamedia, Morocco
}

\begin{abstract}
According to the 5th assessment report of the Intergovernmental Panel on Climate Change (IPCC), the temperature is projected to rise over the 21 st century under all assessed emissions scenarios while precipitation will likely decrease, thus reducing renewable surface water and groundwater resources in most dry subtropical regions such as Morocco. Moreover, most projections of global circulation models predict a dryer future for North African countries. This work aims to assess the impact of climate variability on water resources in the coastal sub-basin of El Jadida-Safi, located in the Oum Er-Rbia basin. In order to determine future climate projections in the coastal sub-basin by the year 2099, we are using SDSM, a statistical downscaling tool based on both observed and anthropogenic emission scenario data for the pessimistic scenario RCP 8.5 and the optimistic scenario RCP 4.5. Results will help decision-makers and stakeholders better manage their water resources, prepare for extreme hydrological hazards, and enhance development planning in the river basin.
\end{abstract}

\section{Introduction}

Since 1950, changes in climate events have been observed worldwide, including an increase in temperature and a decrease in precipitations [1]. Climate change is projected to increase water demand, especially for irrigation in dry subtropical regions, and reduce surface and groundwater resources [2-7].

North African countries are expected to be the most affected by climate hazards, climate studies predict that temperature is to rise between 2 and $3^{\circ} \mathrm{C}$ while precipitation is to decrease between $10 \%$ and $20 \%$ until 2050 [8-9] (Paeth et al. 2009, Christoph et al. 2010, Schilling et al. 2012). Morocco already bears the effects of climate change, with a sequence of droughts or extreme precipitation events leading to floods. According to Modelling System for Agricultural Impacts of Climate Change (MOSAICC) which is a dynamic tool developed by the Food and Agriculture Organization (FAO) between 2013 and 2015, the average temperature could increase from 1.1 to $1.6^{\circ} \mathrm{C}$ by 2030 , from 2.3 to $2.9^{\circ} \mathrm{C}$ in 2050 , and from 3.2 to $4.1^{\circ} \mathrm{C}$ in 2080 . At the same time, the precipitation could decrease by $14 \%$ in 2030 , from 13 to $30 \%$ in 2050 , and from 21 to $36 \%$ in 2080 .

Water resources management studies require fine resolution climate data [10] (Timbal et al. 2009). However, General Circulation Models (GCM) have coarse resolutions, which make their application at the level of regional or local scales minimal. Consequently, downscaling methods were developed to span the spatial gap between the coarse GCMs outputs and the hydroclimatic basin variables [11-13].
In this study, future precipitation and temperature of the sub-basin were projected using a statistical downscaling approach under two RCP scenarios; results follow the trends of climate change projection worldwide. Some adaptation measures implemented at the level of the study area to face these imminent threats were discussed.

\section{Study area}

The coastal sub-basin of El Jadida - Safi is located southwest of the Oum-Er-Rbia basin. Its total area is of the order of $13070 \mathrm{~km} 2$. The basin includes the major cities of Safi, El Jadida, and Sidi Bennour, the industrial zone, and the port of Jorf Lasfar (Figure 1).

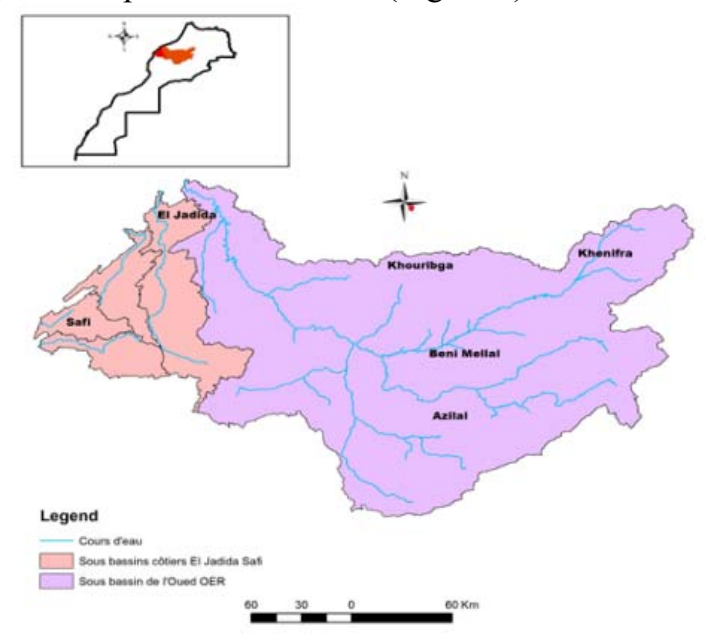

Fig 1. Location of El Jadida-Safi sub-basin

\footnotetext{
* Corresponding author: elazharimounia@gmail.com
} 
A temperate coastal climate characterizes the subbasin; annual precipitation varies between 200 and 300 $\mathrm{mm}$, while temperature varies between 7.5 and $26^{\circ} \mathrm{C}$. Surface water inputs to the study area are of the order of $50 \mathrm{Mm} 3 /$ year. In addition, all non-consumed water from the upstream of Oum Er- Rbia basin estimated at 1590 $\mathrm{Mm} 3 /$ year are recovered by $\mathrm{Al}$ Massira dam and its compensators (Imfout, Daourat, and Sidi Said Maachou) and are transferred mainly to the coastal sub-basin of El Jadida - Safi. As to groundwater resources, they are generally contained in the aquifers of Sahel -Doukkala over an area of $6350 \mathrm{Km} 2$ and allow the supply of more than $43 \mathrm{Mm} 3 /$ year.

Mobilized water is mainly used to meet the needs for drinking and industrial water of the different urban and rural agglomerations in the sub-basin; it is also used to irrigate the Doukkala perimeter.

\section{Statistical Downscaling}

The statistical downscaling technique assumes that the relationships between the GCM outputs and the hydroclimatic catchment variables for the past observed climate are equally valid for the future, under changing climate [14]. In this study, multiple linear regression was used to project future temperature and precipitation at the level of the coastal sub-basin of El Jadida-Safi under two climate scenarios, RCP4.5, and RCP8.5.

The general equation for statistical downscaling based on the transfer function is:

$$
R=F(X)
$$

Where $\mathrm{R}$ represents the local climate variable, known as the predictand (precipitation, temperature), $\mathrm{X}$ is the set of GCM generated large-scale climate variables (predictors), and $\mathrm{F}$ is the stochastic or deterministic function that establishes the relationship between the predictands $(\mathrm{R})$ and predictors $(\mathrm{X})$ [15]. Using twenty-six predictors from the second generation Canadian Earth System Model (CanESM2) developed by the Canadian Centre for Climate Modelling and Analysis (CCCma) of Environment and Climate Change in Canada for RCP 4.5 and 8.5 scenarios for the period 1961-2100, we statistically downscaled both temperature and precipitation data taken from the meteorological station of Al Massira (Table 1). The predictors with the best correlation were chosen to project future climate from 2020 until the year 2100 (Table 1).

Table 1. Meteorological station characteristics

\begin{tabular}{|c|c|c|c|c|}
\hline \multicolumn{2}{|c|}{ Station } & $\begin{array}{c}\text { Data } \\
\text { period }\end{array}$ & \multicolumn{2}{c|}{ Predictors } \\
\hline \multicolumn{2}{|c|}{ Al Massira } & \multirow{2}{|c|}{$1984-$} & Precipitation & Temperature \\
\cline { 1 - 1 } $\begin{array}{c}\text { Longitude } \\
-7.63\end{array}$ & Latitude & 2017 & $\begin{array}{c}\text { P8_fgl } \\
\text { p8_ugl } \\
\text { prcpgl }\end{array}$ & $\begin{array}{c}\text { p500gl } \\
\text { p850gl } \\
\text { tempgl }\end{array}$ \\
\hline
\end{tabular}

Results of statistical downscaling for Al Massira station follow projections for the Oum Er-Rbia basin and Morocco in general with an increase in temperature and a decrease in precipitations. It will decrease by $3.21 \%$ for the RCP4.5 scenario and $3.44 \%$ for the RCP8.5 scenario for precipitation. In contrast, the temperature will increase by $2{ }^{\circ} \mathrm{C}$ for the $\mathrm{RCP} 8.5$ scenario and by $2.2^{\circ} \mathrm{C}$ for the RCP4.5 scenario (Figures 2 and 3).

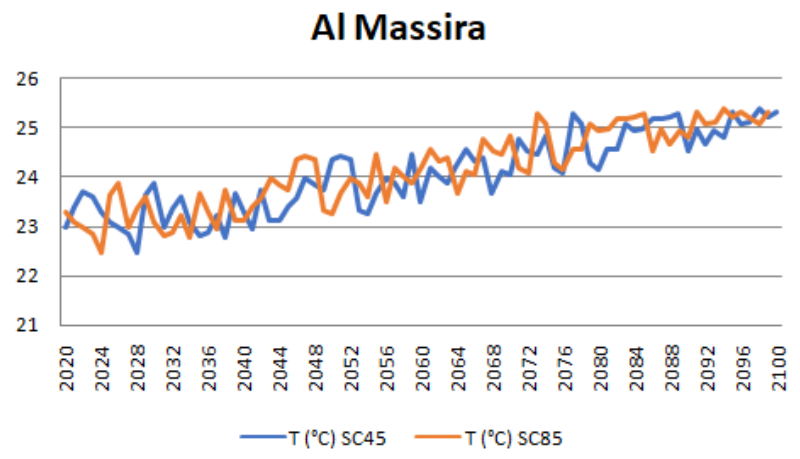

Fig 2. Evolution of temperature for both scenarios from 2020 to 2100

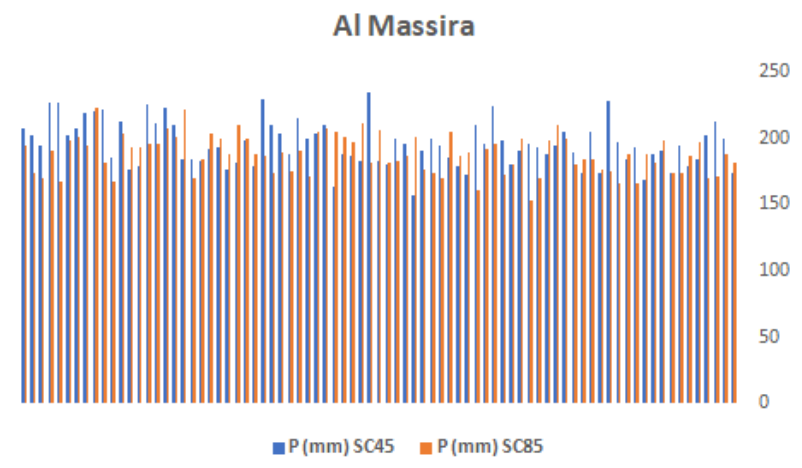

Fig 3. Evolution of precipitation for both scenarios from 2020 to 2100

Observed data over 37 years was used for calibration (1980-1998) and validation (1999-2017). The results of these two steps for precipitation and temperature are shown in Table 2 . The values of $\mathrm{R} 2$ indicate a good correlation for temperature. However, for precipitation, and as already stated before, it is challenging to develop a perfect multiple regression equation because of the conditional behavior of precipitation.

Table 2. SDSM calibration and validation results for $\mathrm{Al}$ Massira station

\begin{tabular}{|c|c|c|c|}
\hline \multirow{2}{*}{ Station } & \multirow{2}{*}{ Predictand } & \multicolumn{2}{|c|}{$\mathbf{R}^{2}$} \\
\cline { 3 - 4 } & & Calibration & Validation \\
\hline $\begin{array}{c}\text { Al } \\
\text { Massira }\end{array}$ & Precipitation & 0.309 & 0.532 \\
\cline { 2 - 4 } & Temperature & 0.946 & 0.960 \\
\hline
\end{tabular}

\section{Adaptation measures}

Considering the alarming climate projections in the subbasin, and ensuring rational and sustainable management of water resources in the area to belay water availability for all users under acceptable conditions, policymakers and decision takers must integrate adaptation measures in programs and plans bound to water resources 
management. In recent years, at the level of Morocco and the study area in specific, several measures were implemented, such as the project of desalination of seawater launched by the Cherifien Office of Phosphates and which will reduce the excessive use of groundwater and allow the supply of 100 million $\mathrm{m} 3$ /year through the plants of El Jadida and Safi. Besides, the Office of Agricultural Development of Doukkala adopted a strategy to rationalize and enhance the value of water use that involves several actions that limit water loss, improve performance of hydraulic structures and encourage users to save water by introducing new water-saving techniques leading to $40 \%$ of water savings [16-17].

\section{Conclusion and recommendations}

Results of statistical downscaling using SDSM for the sub-basin of El Jadida Safi confirm results and predictions of previous studies in the North African region. In fact, in the coming years, temperatures will tend to increase, while for precipitation, these will decrease with the alternation of dry and wet years.

These trends will indeed have a direct impact on water resources in the region. Thus, adaptation measures are necessary to maintain consistent offers to respond to different demands.

In order to quantify the impact of climate change on available water resources, the next step should focus on hydrological modelization of the sub-basin using available data and the results of this statistical downscaling.

\section{References}

1. IPCC, Climate Change 2014: Synthesis Report. Contribution of Working Groups I, II and III to the Fifth Assessment Report of the Intergovernmental Panel on Climate Change [Core Writing Team, R.K. Pachauri and L.A. Meyer (eds.)]. IPCC, Geneva, Switzerland, 151 pp (2014)

2. I.P. Holman. Hydrogeol. J. 14, 637-647 (2006)
3. B.E. Jiménez Cisneros, T. Oki, N.W. Arnell, G. Benito, J.G. Cogley, P. Döll, , T. Jiang, S.S. Mwakalila. Freshwater resources, 229-269 (2014)

4. X. Wang, J. Zhang, S. Shahid, E. Guan, Y. Wu, J. Gao, R. He. Mitig. Adapt. Strategies Glob. Change, 81-99 (2014)

5. K.E. Trenberth, J.T. Fasullo, TG, Shepherd. Nature Clim Change, 5, 725-730 (2015)

6. J.M. Kirby, M. Mainuddin, F. Mpelasoka, M.D. Ahmad, W. Palash, M.E. Quadir, S.M. Shah-Newaz, M.M. Hossain. Clim. Chang., 135, 481-491(2016)

7. J. Xia, Q.Y. Duan, Y. Luo, Z.H. Xie, Z.Y. Liu, X.G. Mo. Advances in Climate Change Research, 8(2), 6367 (2017)

8. H. Paeth, K. Born, R. Girmes. Journal of Climate, 22, 114-132 (2009)

9. M. Christoph, A.H. Fink, H. Paeth. Climate scenarios. In: Speth, P., Christoph, M., Diekkrüger, B. (Eds.), Springer, Heidelberg, 402-425 (2010)

10. J. Schilling, K. P. Freier, E. Hertig, J. Scheffra. Ecosystems \& Environment, 156, 12-26 (2012)

11. B. Timbal, E. Fernandez, Z. Li. Environmental Modelling \& Software, 24(3), 341-358 (2009)

12. R.L. Wilby, T.M.L. Wigley. Prog Phys Geog , 21, 530-548 (1997)

13. R.L. Wilby, S.P. Charles, E. Zorita, B. Timbal, P. Whetton, L.O. Mearns. Supporting material to the IPCC, 3-21 (2004)

14. H.J. Fowler, R.L. Wilby, Water Resour. Res., 46, W03525 (2010)

15. H. Von Storch, E. Zorita, U. Cubasch. J. Climate, 6(6), 1161-1171 (1993)

16. S. Beecham, M. Rashid, \& R.K. Chowdhury. Int. J. Climatol., 34, 3654-3670 (2014)

17. A. Guemimi, Séminaire sur la modernisation de l'agriculture irriguée, Rabat, Maroc. IAV Hassan II, 10 p. (2004) 